\title{
Rare complication: Persistent hiccups
}

\author{
Ebru Tarıkçı Kılıç*, Mehmet Salim Akdemir and Haluk Kılıç \\ Department of Anaesthesiology and Reanimation, Ümraniye Training and Research Hospital, İstanbul, Turkey
}

\begin{abstract}
Cervical epidural steroid injections have been commonly used in the treatment of cervical radicular pain. When appropriate radiographic, pharmacologic tecniques are used these procedures are safe. The literature consists of only few cases consisting of hiccups after epidural steroid injections. Here we present a rare case of persistent hiccups after a cervical epidural steroid injection of a 70 years old male patient with chronic pain due to disc bulges in $\mathrm{C} 5$ - $\mathrm{C} 7$.
\end{abstract}

\section{Introduction}

Hiccups are common conditions due to the unknown causes and usually need no treatment Hiccups caused by anesthesia are usually of the chronic type and don't become persistent. Anesthesia, along with central nervous system and metabolic problems can cause long-term hiccups. Hiccups can be short-term or can last for hours. They go away on their own or via one of the home remedies people like to try, like holding your breath. However, hiccups that last more than 48 hours are called persistent hiccups, and those that last longer than a month are said to be intractable $[1,2]$.

Corticosteroids are the drug groups referenced most frequently in the literature as being associated with hiccups. It has been proposed that corticosteroids lower the threshold for synaptic transmission in the midbrain and directly stimulate the hiccup reflex arc [2].

\section{Case Presentation}

A 70 year old female patient presented to the anesthesia department for treatment of chronic cervical pain continuing five years. She had no relief with analgesics including NSAID, tramadol or any responses to physiotheraphy. Surgery was found to have high risks due to the co morbid illnesses. Her medical history consisted of COPD for five years and hypertension for ten years. She was not allergic to any drugs on physical examination she was found to have neck pain and right upper sided numbness. Her range of motion decreased while extension. Reflexes were normal. A cervical steroid injection was decided and performed at C7-T1 level.

After getting informed consent of the patient, she was taken in prone with the neck in the neutral position. All vital signs, pulse oximetry, heart rate respiratory rate and temperature were within normal limits. The right C7-T1 epidural space was identified using fluoroskopy. A 22 gauge Tuohy was advanced to the epidural space using loss of resistance technique. After 2 hours the patient started to complain of hiccups, which was not associated with other symptoms. The patient was treated with $10 \mathrm{mg}$ haloperidol and $10 \mathrm{mg}$ metoclopramide every 8 hours. There was no improvement in clinical condition. Three days later the hiccups decreased and resolved completely.

\section{Discussion}

Complications from epidural injections can present in different situations. In our patient the epidural block was performed in the cervical region at the level of $\mathrm{C} 7 \mathrm{~T} 1$ and the patient developed hiccups 2 hours after the block.

Local anesthetics used in epidural injections have never been proven to be the exact cause of hiccups. Beyaz and his friends reported persistent hiccups after a single shot posterior lumbal steroid injection. Solution consisting of $80 \mathrm{mg}$ triamcinolone acetate and 20 mg bupivacaine was slowly administered [3]. The patient developed hiccups 15 hours later. These hiccups lasted 3 days and subsided spontaneously.

Slipman et al. reported hiccups after thoracic epidural steroid injection using betamethasone and $1 \%$ lidocaine. They attributed the cause of hiccups to the steroid injection [4].

Mc Allister used a mixture of $0.08 \%$ bupivacaine and $80 \mathrm{mg}$ triamcinolone in the lumbar region. Hiccups started 1 hour later and persisted for 5-7 days. Kaydu and friends administered $20 \mathrm{ml}$ of drug mixture of celestone $6 \mathrm{mgr}(1 \mathrm{cc})$ and bupivacaine $15 \mathrm{mgr}(3 \mathrm{cc})$ and 16 $\mathrm{ml}$ saline solution carefully for back pain in the lumbar epidural region. At $20^{\text {th }} \mathrm{h}$, after the injection hiccups were started and persisted for 3 days $[5,6]$.

The reason of hiccups after epidural steroid injection has not yet been explained. The volume effect of solution given into the epidural space may change the balance of the cerbrospinal fluid volume. Mechanism and incidence of hiccups due to steroids are not known, but steroids effect the neurotransmitters of the brainstem and have neuroexcitatory properties. Bupivacaine alone or in combination with steroids can cause hiccups. Anesthesiologists should be aware of complications for cervical epidural injections as epidural steroid injections are increasing currently. Hiccups should always be on consider.

\section{Conclusion}

We must inform the patients who will have an epidural injection about the side effects. It is a rare but bening complication.

*Correspondence to: Ebru Tarıkçı Kılıç, Department of Anaesthesiology and Reanimation, Ümraniye Training and Research Hospital, İstanbul, Turkey, Tel: +05063306640; E-mail: ebru.tarkc@yahoo.com

Key words: cervical, epidural, steroids, hiccups

Received: August 09, 2018; Accepted: August 21, 2018; Published: August 28, 2018 


\section{Referances}

1. Hung YM, Miller MA, Patel MM (2003) Persistent hiccups associated with intravenous corticosteroid therapy. J Clin Rheumatol 9: 306-9. [Crossref]

2. Launois S, Bizec JL, Whitelaw WA, Cabane J, Derenne JP (1993) Hiccup in adults: An overview. Eur Respir J 6: 563-75. [Crossref]

3. Beyaz SG (2012) Persistent hiccup after lumbar epidural steroid injection. $J$ Anaesthesiol Clin Pharmacol 28: 418-9. [Crossref]
4. Slipman CW, Shin CH, Patel RK, Braverman DL, Lenrow DA, et al. (2001) Persistent hiccup associated with thoracic epidural injection. Am J Phys Med Rehabil 80: 618-21. [Crossref]

5. McAllister RK, McDavid AJ, Meyer TA, Bittenbinder TM (2005) Recurrent persistent hiccups after epidural steroid injection and analgesia with bupivacaine. Anesth Analg 100: 1834-6. [Crossref]

6. Kaydu A, Kılıç ET, Gökçek E, Akdemir MS (2017) Unexpected Complication after Caudal Epidural Steroid Injection: Hiccup. Anesth Essays Res 11: 776-777. [Crossref]

Copyright: (O2018 Kılı̧ ET. This is an open-access article distributed under the terms of the Creative Commons Attribution License, which permits unrestricted use, distribution, and reproduction in any medium, provided the original author and source are credited. 